East African Journal of Science, Technology and Innovation, Vol. 1 (1): 2019, 1-10.

This article is licensed under a Creative Commons license, Attribution 4.0 International (CC BY 4.0)

\title{
A comparison between indirect ELISA and tuberculin skin test in the diagnosis of bovine tuberculosis in Kenya
}

\author{
1*MUASYA D., 1GITAU G., 1THAIYAH G., 1GAKUYA D. ${ }^{2}$ VANLEEUWEN J., ${ }^{3 M B A T H A}$ P. \\ ${ }^{1}$ Department of Clinical Studies, Faculty of Veterinary Medicine, University of Nairobi P.O. Box 29053-00625 Kangemi. \\ ${ }^{2}$ Department of Health Management, Atlantic Veterinary College, University of Prince Edward Island. Atlantic Veterinary \\ College, $337 \mathrm{~N}$. \\ ${ }^{3}$ Central Veterinary Investigation Laboratories, State Department of Veterinary Services, Nairobi, Kenya P.O. Box 66730 - 00800 , \\ Nairobi. \\ *Corresponding author: dmuasya@upei.ca
}

\begin{abstract}
Bovine tuberculosis (BTB) is an important zoonotic disease which has remained persistent in many areas of the World. Control and eradication has proved problematic due to the challenges in effective screening and diagnosis. Limited information on the status of BTB in Kenya presents a need to investigate its occurrence in cattle population. The study was carried out using an indirect antibody Enzyme Linked Immunosorbent Assay (ELISA-IDEXX-USA) to assess the agreement with Comparative Intradermal Tuberculin Test (CITT) test results between August and December 2013 in Laikipia County. The study also determined the apparent prevalence of cattle BTB antibodies in Laikipia County. A total of 276 bovine serum samples were tested using MPB70 and MPB83 recombinant proteins as capture antigens in the ELISA kit. Data were recorded in Microsoft Excel and exported to SPSS 16.0 for analysis. Apparent prevalence was calculated as a proportion at $95 \%$ CI, Kappa statistics computed, and test of significance assessed by Chi-square and Fisher exact test. The results showed an individual animal apparent prevalence of 3.9\% $(11 / 276)$ and a herd prevalence of $58.3 \%(7 / 12)$. There was no significant association between BTB infection and both animal level factors, breed and sex. Kappa agreement test between ELISA test and TST showed a good agreement at $\mathrm{K}=$ 0.65. This study reported the prevalence of BTB in cattle for the first time in Laikipia County Kenya using the IDEXX ELISA. The ELISA test was comparable to the tuberculin test which is used as the gold standard for screening TB on live animals. The two tests can be used alongside for series or parallel interpretation to achieve desirable diagnostic sensitivity and specificity in disease control programs.
\end{abstract}

Keywords: Bovine; Tuberculosis; Kenya; Indirect Antibody ELISA; TST

\section{Introduction}

Bovine tuberculosis (BTB) is a zoonotic and a chronic infectious disease of cattle caused primarily by Mycobacterium bovis (M. bovis) and characterized by development of avascular granulomatous nodules. Most body tissues and organs can be affected, but lesions are most frequently seen in the lymph nodes of the head and thorax, in the intestines, lungs, liver, spleen and peritoneum (Clarke, 1998). Mycobacterium bovis primarily infects cattle but it can infect other animals and humans (Kaneene and Pfeiffer 2006, Thoen et al., 2006). Mycobacterium caprae has been identified as a cause of BTB in some parts of central Europe (Naranjo et al., 2008).
Cite as: Daniel Muasya, et al., 2019 A comparison between indirect ELISA and tuberculin skin test in the diagnosis of bovine tuberculosis in Kenya, East African Journal of Science, Technology and Innovation 1(1): 1-10.
Received: $\quad 16 / 05 / 19$

Accepted: $08 / 08 / 19$

Published: 25/10/19 
The genus Mycobacterium consists of more than 100 species and most of these are found in the environment and are not normally pathogenic to humans or animals however a small number of them are pathogenic to various species of animals (Sam et al., 2008). BTB is endemic in many areas of the World and is associated with significant economic losses due to reduced cattle productivity and cost of control and eradication programs in addition to being a zoonotic pathogen that can infect humans (Steele, 1995). Bovine tuberculosis has a worldwide distribution with some countries of Europe having made a lot of success in control programs, it is however still endemic in Africa (Ayele et al., 2004, Alvarez et al., 2012). A study in Kenya and Tanzania using Single Comparative Intradermal Tuberculin Test (SCITT) showed prevalence of $4 \%$ to $6 \%$ and $1.28 \%$ to $2.37 \%$ respectively in both countries (Mugabi et al., 2016). In Kenya a study reported prevalence of M. bovis at $2.05 \%$ among slaughter cattle around Nairobi in 2009 (Gathogo et al., 2012). A recent study employing examination of direct stained smears and recovered media isolates on slaughter lesions in Laikipia Kenya found $0.3 \%$ of the carcasses having zoonotic mycobacteria (Kuria et al., 2018). There is little transmission awareness knowledge about BTB by communities in both cattle keeping and noncattle keeping farming families in Kenya (Kangethe et al., 2007).

Eradication of BTB has been difficult to achieve in various countries due to the presence of wildlife reservoirs, increased animal movement and/or pastoral practices and limitation of available diagnostic and screening methods (Schiller et al., 2010 and Farias et al., 2012). Diagnosis of BTB remains extremely challenging and currently there is no one single test that can fulfill all the criteria necessary to identify infected animals (Schiller et al., 2010). A number of new specific antigens have been tested on immunoassays for the diagnosis of BTB. The capture antigens MPB70 and MPB83 used in this IDEXX ELISA kit have shown good diagnostic reliability (Amadori et al., 2002 and Farias et al., 2012).

In Kenya, most studies done have concentrated on post-mortem diagnosis in slaughter lesions. Diagnosing on live animals through CITT and serological methods can be of great importance in understanding risk factors and contributing to control programs information in different production systems. This study aimed to compare the antibody ELISA and CITT diagnostic methods and report the agreement between the two tests in the diagnosis of BTB.

\section{Materials and Methods}

\section{Study Area and Design}

The study was purposively carried out in Laikipia County, Kenya due to availability of sera samples and existing records for animals that had earlier been used for Comparative Intradermal Tuberculin Test (CITT). Blood for sera preparation from different farms in Laikipia County was collected from between 2011 and 2013 with the animals undergoing CITT. A crosssectional study employing indirect antibody ELISA test (IDEXX-USA) was carried out between August 2013 and December 2013 to screen for Bovine Tuberculosis (BTB). The CITT had been done in 2012 and the sera stored at the Central Veterinary Investigation Laboratories (CVIL), Kabete Nairobi. Data available for the sera included the farm, sub-county, breed and sex of the animals. The samples were from all the three sub counties of Laikipia County.

\section{Sample size determination}

A total of 276 samples were tested due to the availability of test kits against a minimum proportion sample calculation of 87 assuming a prevalence of $6 \%$ (Dohoo et al., 2012). The a priori estimate of $6 \%$ was informed by one of the studies showing the highest prevalence of BTB in Kenya (Lekolool 2011).

\section{Laboratory analysis}

The antibody ELISA test was carried out in accordance with the manufacturer's instructions. Antigen coated plates sufficient for planned samples were tested at a time and withdrawn from the desiccated bag. A total of $100 \mu \mathrm{l}$ (microliters) of the diluted negative control, positive control and serum samples were dispensed in the wells. The wells were covered and incubated at $18-26^{\circ} \mathrm{C}$ for 60 minutes then washed 3 to 5 times with $300 \mu$ l of wash solution avoiding drying in between washes. Thereafter, $100 \mu 1$ of the conjugate was then dispensed into the wells, incubated for 30 minutes and then washed 3 to 5 times with $300 \mu$. The substrate was 


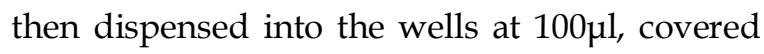
and incubated for 15 minutes. The stop solution was then dispensed last into the wells and absorbance optical density (OD) read at $450 \mathrm{~nm}$. The presence or absence of antibody to M. bovis is determined by calculating the sample to positive $(\mathrm{S} / \mathrm{P})$ ratio for each sample. The $\mathrm{S} / \mathrm{P}$ ratio is derived by subtracting the mean kit negativecontrol optical density (OD) from each sample and dividing this value by the corrected positivecontrol value (mean positive-control OD minus mean negative-control OD). An S/P greater or equal to 0.30 is considered positive for $M$. bovis antibodies.

\section{Statistical Analysis}

Data from the antibody ELISA results was stored in Excel 2007 (Microsoft Corporation, USA) and exported to SPSS 16.0 (SPSS Inc., 233 South Wacker Drive, Chicago IL) for analysis. Apparent prevalence was determined as a proportion of the positive cases out of total positives at $95 \%$ confidence interval (CI). The kappa statistics was used to estimate the degree of agreement between the two diagnostic tests. Chi-square and Fisher exact test techniques were applied to test significance of association between BTB infection status and animal- and farm-level predictors.

\section{Results}

The distribution of the samples collected from the 12 farms in three sub counties of Laikipia County and their test status are shown in Table 1. Laikipia East had the highest number of samples $171 / 276(70 \%)$ with $9 / 171$ (5.3\%) being positive to $M$. bovis antibodies. Laikipia North and West districts had only one positive sample each with the latter contributing the least number of samples. The overall apparent prevalence was $3.99 \%(11 / 276)$.

The farm with the highest number of samples was $33.7 \%(93 / 276)$ with the least being $0.4 \%$ $(1 / 276)$ (Table 2). The farm with highest number of positive samples was $4.5 \%(3 / 67)$ and seven farms $(7 / 12)$ had at least one positive sample while the other five ranches/farms did not have any positive animal. Out of 12 farms sampled, the prevalence was $58.63 \%(7 / 12)$. Out of the 276 samples tested, $94.6 \%(261 / 276)$ were from female animals.
Table 1

Number of Bovine tuberculosis positive samples to ELISA from Laikipia County by Sub County

\begin{tabular}{|c|c|c|}
\hline Sub county & Number positive & 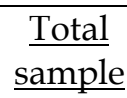 \\
\hline Laikipia & & \\
\hline West & $1(1.09 \%)$ & 92 \\
\hline Laikipia East & $9(5.26 \%)$ & 171 \\
\hline Laikipia North & $1(7.67 \%)$ & 13 \\
\hline Total & $11(3.99 \%)$ & 276 \\
\hline
\end{tabular}

About $6.7 \%(1 / 15)$ of serum samples from male animals tested positive for antibodies against $M$. bovis while $3.8 \%(10 / 261)$ of the serum samples from females tested positive. There was no significant association between sex of the animal and occurrence of BTB (Fisher Exact test, p= $0.9310)$.

Table 2

Samples tested from Laikipia County by farms, indicating numbers of positive animals to Bovine tuberculosis ELISA

\begin{tabular}{cccc}
\hline $\begin{array}{c}\text { Farm } \\
\text { Number }\end{array}$ & $\begin{array}{c}\text { Number } \\
\text { positive }\end{array}$ & $\underline{\text { Total }}$ & $\begin{array}{c}\% \\
\text { Positive }\end{array}$ \\
\hline 1 & 3 & 67 & 4.48 \\
2 & 0 & 17 & 0 \\
3 & 0 & 1 & 0 \\
4 & 0 & 6 & 0 \\
5 & 2 & 30 & 6.67 \\
6 & 0 & 4 & 0 \\
7 & 1 & 5 & 20 \\
8 & 1 & 93 & 4.35 \\
9 & 2 & 35 & 5.71 \\
10 & 1 & 6 & 16.67 \\
11 & 1 & 5 & 20 \\
12 & 0 & 7 & 0 \\
Total & 11 & 276 & 3.99 \\
\hline
\end{tabular}

The Boran breed had the highest number of samples that were tested at $51.8 \%(143 / 276)$ with Ankole having the least number at only one sample (Table 3). About 9.4\% (26/ 276) did not have the breed recorded during sampling. The 
highest breed BTB prevalence was in Ayrshire at $7.1 \%(2 / 28)$ followed by Friesian with $6.85 \%$ (3/44), Boran with $3.4 \%(5 / 143)$ and Zebu breed with $3.1 \%(1 / 32)$. Ankole and Brown Swiss breeds, and the 26 samples without breed were all negative. When the animals were classified by breed into two groups, exotic (Bos taurus) and indigenous (Bos indicus), there was no statistically significant association $(\mathrm{P}=.4)$

Table 3

Prevalence of Mycobacterium bovis by Breeds in Laikipia County

\begin{tabular}{|c|c|c|c|}
\hline Breed & $\frac{\text { Number }}{\text { positive }}$ & Total & $\stackrel{\frac{\%}{0}}{\text { Positive }}$ \\
\hline Ayrshire & 2 & 28 & 7.1 \\
\hline Friesian & 3 & 44 & 6.8 \\
\hline Boran & 5 & 143 & 3.5 \\
\hline Zebu & 1 & 32 & 3.1 \\
\hline Ankole & 0 & 1 & 0 \\
\hline Brown swiss & 0 & 2 & 0 \\
\hline $\begin{array}{l}\text { Non- } \\
\text { specified }\end{array}$ & 0 & 26 & 0 \\
\hline Total & 11 & 276 & 3.99 \\
\hline
\end{tabular}

\section{Comparison of antibody ELISA and CITT}

Out of the 276 samples tested from Laikipia County, 254 had tuberculin skin test results that were interpreted and recorded. Eight (8) samples tested positive on both CITT and ELISA with 239 tested negative for both with an observed proportional agreement of 0.97 (97\%). Four (4) samples tested positive for CITT but tested negative for ELISA while three (3) testing positive for ELISA tested negative for CITT while 239 tested negative for both. Kappa showed strong agreement between the two M. bovis tests at $\mathrm{K}=0.65$.

\section{Discussion}

This study was performed on stored bovine serum samples to estimate the status of BTB infection in Laikipia County using an antibody ELISA and compare the test with CITT results. The use and performance of the IDEXX $M$. bovis antibody ELISA kit has been evaluated in various studies (Eyob et al., 2014 and Waters et al., 2011). Capture antigens, especially recombinant MPB70 and MPB83 have been used in antibody ELISA as alternative and/or complementary diagnostic tools to improve detection of cattle that do not react to tuberculin skin test (Smith et al., 2006). The MPB83 and MPB70 are major antigens highly expressed by $M$. bovis and considerably less abundantly expressed by $M$. tuberculosis (Juarez et al., 2001). The MPB83 antibodies have been detected in cattle infected with Mycobacterium kansasii, making it the only known Mycobacterium species cross reacting with the antigen (Green et al., 2009, Waters et al., 2000).

The overall prevalence of BTB reported in seven Counties of Kenya by Muasya, 2015 was 3.57\% with a range of $4.74 \%$ in the County with highest prevalence and $0 \%$ the least. Like other countries in the region, Kenya lacks adequate data and reference records on BTB status. A past study in Kenya reported a $2.0 \%$ prevalence of $M$. bovis among slaughter cattle in two abattoirs around Nairobi (Gathogo et al., 2012). The origin of cattle in that study was 18 counties of Kenya covering approximately $77 \%$ of the landmass. This is lower than what this study found in Laikipia County. Another study using TST reported way higher prevalence of $10 \%$ in dairy and non-dairy herds around Nairobi area (Kang'ethe et al., 2007). A study in Kenya investigating the epidemiology of BTB at the wildlife-livestock interface in Maasai Mara and Amboseli ecosystems in the southern part of Kenya reported a prevalence of $14.8 \%$ in wildlife compared to an overall prevalence of 2.3\% in livestock (Lekolool 2011). The findings of this study are similar to the overall findings of Lekolool however he reported a bigger variation between wildlife and livestock. Laikipia County being a wildlife area, a similar pattern could be expected.

Elsewhere, an estimated prevalence of less than $1 \%$ was reported in a study conducted around Dar-es-Salaam area using single Intradermal Tuberculin Test (SITT) with $6.8 \%$ being doubtful (Weinhaupl et al., 2000). An animal-level prevalence of $2 \%$ and a herd-level prevalence of $51 \%$ were reported in cattle among the pastoral herds of Uganda's Karamoja region (Oloya et al., 2006 and Oloya et al., 2007). The herd-level prevalence is similar to what we found in this study however the animal-level prevalence reported a notable difference.

Unlike in our study a cross-sectional risk factors study conducted in Tanzania from 1994 to 1997, 
revealed that male cattle were significantly more infected by BTB than female animals (Kazwala et al., 2001). Another across-sectional study in Uganda from 2006 to 2007 showed significantly more females positive to the skin test than males (Inangolet et al., 2008). However, in the Ugandan study, there was no significant association between age of the animal and BTB occurrence and this may have meant that the animals were not living long enough to acquire the infection given that BTB is generally a chronic disease. In epidemiological studies carried out in Zambia and Tanzania it was observed that the duration of exposure increases with age (Cook et al., 1996 and Cleaveland et al., 2007). In Laikipia County, the results showed a good Kappa between the two $M$. bovis tests at $\mathrm{K}=0.65$ according to the classification by Altman (1991). A similar Kappa test comparison between TST and ELISA test utilizing MPB70/MPB83 capture antigens in Brazil demonstrated adequate agreement beyond that due to chance with a Kappa of 0.688 (Souza et al., 2008).

\section{Conclusion}

This study showed that sex and breed were not significantly associated with BTB infection. The performance of the ELISA test showed strong agreement beyond that due to chance when compared to the tuberculin skin test. Therefore, the use of the antibody ELISA is recommended since it is feasible, reliable, cheaper and less time consuming.

\section{Acknowledgements}

This study was made possible through the support of Department of Veterinary Services who provided the bovine sera and laboratory facility and the animal records and the Department of Clinical Studies at the University of Nairobi supporting and approving the study.

\section{References}

Altman D. G. (1991). Practical statistics for medical research. London: Chapman and Hall.

Alvarez, J., Perez, A.M., Bezos, J., Casal, C., Romero, B., Rodriguez-Campos, S., Saez
Liorente, J.L., Diaz, R., Carpintero, J., de Juan, L. and Dominguez, L. (2012). Eradication of bovine tuberculosis at a herd-level in Madrid, Spain: study of within-herd transmission dynamics over a 12 year period. BMC Veterinary Research 8: 100.

Amadori M., Lyashchenko K. P., Gennaro M. L., Pollock J. M., Zerbini I. (2002). Use of recombinant proteins in antibody tests for bovine tuberculosis. Vet Microbiol 85:379389.

Ayele, W. Y., Neill, S. D., Zinsstag, J., Welss, M. G and Pavlik, I., (2004). Bovine tuberculosis: an old disease but a new threat to Africa. International Journal of tuberculosis and lung disease, 8, 924-937

Clarke, C.F. (1998). Tuberculosis. The Merck veterinary manual 8 th edition. Merck and Co., INC. USA.

Cleaveland S., Shaw D.J., Mfinanga S.G., Shirima G., Kazwala R.R., Eblate E., Sharp M., (2007). Mycobacterium bovis in rural Tanzania: risk factors for infection in human and cattle populations, Tuberculosis, 87:30-43.

Cook A.J., Tuchili L.M., Buve A., Foster S.D., Godfrey F. P., Pandey G.S., McAdam K.P. (1996). Human and bovine tuberculosis in the Monze district of Zambia a cross-sectional study, British Veterinary Journal, 152:37-46.

Dohoo, I., Martin W. and Stryhn H., (2003). Sample size: Veterinary Epidemiologic Research. AVC, Prince Edward Island, p706.

Eyob H., Gobena A., John C., Ketema T., Adane W., Teshale S. and Olifan Z. (2014). Performance Evaluation of Mycobacterium bovis Antibody Test for the Diagnosis of Bovine Tuberculosis in Ethiopia, Journal of Animal Diseases, 3 (3): 33-38.

Farias T. A., Araújo F. R., Osório S. L. A. R., Jorge K. S. G., Ramos C. A. N., Souza I. F., Azambuja A., Soares C. O., Silva M. R., Pellegrin A. O. (2012). ELISA based on recombinant MPB70 and P27 for detection of antibodies against Mycobacterium bovis. The Journal of Tropical Pathology 41:155-162. 
Gathogo S. M., Kuria J. K. N. and Ombui J. N. (2012). Prevalence of bovine tuberculosis in slaughter cattle in Kenya: a postmortem, microbiological and DNA molecular study. Tropical Animal Health Production, 44:17391744.

Green, L. R., Jones, C. C., Sherwood, A. L., Garkavi, I. V., Cangelosi, G. A., Thacker, T. C., Palmer, M. V., Waters, W. R., Rathe. C. V., (2009). Single-antigen serological testing for bovine tuberculosis. Clinical Vaccine and Immunology, 16:1309-1313.

Inangolet F.O., Demelash B., Oloya J., Opuda A. J., Skjerve E., (2008). A cross-sectional study of bovine tuberculosis in the transhumant and agro-pastoral cattle herds in the border areas of Katakwi and Moroto districts, Uganda, Tropical Animal Health and Production, 40:501508.

Juarez MD, Torres A, Espitia C, (2001). Characterization of Mycobacterium tuberculosis region containing the mpt83 and mpt70 genes. Microbiology Letters, 203, 95-102.

Kaneene, J.B., Pfeiffer, D., (2006). Epidemiology of mycobacterium bovis in Mycobacterium bovis infection. In: Thoen, C.O, Steel, J.H., Gilsdorf, M.J. (Eds.) Mycobacterium bovis infection in animals and humans, second edition, Blackwell Publishing pp34-49.

Kang'ethe E.K., Ekuttan C. E., Kimani V. N. (2007). Investigation of the prevalence of bovine tuberculosis and risk factors for human infection with bovine tuberculosis among dairy and non-dairy farming neighbour households in Dagoretti Division, Nairobi, Kenya. East African Medical Journal, 84, 11 Supplementary: S92-5.

Kazwala R.R., Kambarage D.M., Daborn C.J., Nyange J., Jiwa S.F.H., Sharp J.M., (2001). Risk factors associated with the occurrence of bovine tuberculosis in cattle in the Southern Highlands of Tanzania, Veterinary Resource Communication, 25:609-614.

Kuria J.K., Akwalu S.K., Muema L.M. (2018). The etiology and public health significance of mycobacteriosis of cattle in Kenya.
International Journal of Mycobacteriology, 7:2516.

Lekolool, Isaac L. (2011). Epidemiological investigation of bovine tuberculosis in the wildlife-livestock interphase in the Masai Mara and Amboseli ecosystems of Kenya. A Thesis in Master of Veterinary Epidemiology and Economics, Department of public Health Pharmacology and Toxicology, University of Nairobi.

Mohammed N., Hailu M. and Gebreyesus M. (2012). Prevalence and zoonotic implications of bovine tuberculosis in Northwest Ethiopia. International Journal of Medicine and Medical Sciences, 2 (9):188-192.

Muasya D.W., (2015). Estimating the prevalence of bovine tuberculosis (BTB) using indirect ELISA test in selected counties of Kenya. Master of Veterinary Medicine, University of Nairobi.

Mugambi J.M., Omwenga S.G., Wesonga H.O., Mbatha P., Gathogo S., Chota A.C., Magwisha H.B., Makondo Z.E., Rukambile E. and Mwakapuja R. (2016). Bovine Tuberculosis In East Africa. African Crop Science Journal, Vol. 24, Issue Supplement s1, pp. 53 - 61

Naranjo V, Gortázar C, Vicente J, de la Fuente J (2008). Evidence of the role of European Wild boar as a reservoir of Mycobacterium tuberculosis complex. Veterinary Microbiology, 127:1-9.

Oloya .J, Opuda-Asibo J., Djonne B., Muma J.B., Matope G., Kazwala R. (2006). Responses to tuberculin among Zebu cattle in the transhumance regions of Karamoja and Nakasongola district of Uganda. Tropical Animal Health and Production, 38: 275-283.

Oloya J., Muma J.B., Opuda-Asibo J., Djonne B, Kazwala R., Skjerve E. (2007). Risk factors for herd-level bovine-tuberculosis seropositivity in transhumant cattle in Uganda. Preventive Veterinary Medicine, 80:318-329.

Sam A., Strain J., McNair S., McDowell W. J. Bovine tuberculosis: (2011). A review of 
Diagnostic tests for Mycobacterium bovis infection in cattle Bacteriology Branch Veterinary Sciences Division Agri-Food and Biosciences Institute.

Schiller, I., Vordermeier, H.M., Waters, W.R., Kyburz, A., Cagiola, M., Whelan, A., Palmer, M.V., Thacker, T.C., Meijlis, J., Carter, C., Gordon, S., Egnuni, T., Hardegger, R., MargHaufe, B., Raeber, A., Oesch, B., (2010). Comparison of tuberculin activity using the interferon- $\hat{\mathrm{I}}^{3}$ assay for the diagnosis of bovine tuberculosis. Veterinary Record, 167:322-326.

Smith NH, Gordon SV, De la Rua-Domenech R, Clifton-Hadley RS, Hewinson RG. (2006). Bottlenecks and broomsticks: the molecular evolution of Mycobacterium bovis. Nature Reviews Microbiology, 4:670-681.

Souza I. F., Elaine S. P., Carlos A. N., Thaís A. F., AnaLuiza A.R., Klaudia S. G., Carlos E. S., Altino S. S., Márcio R. S., Aiesca O. P. and Flábio R. A. (2012). Screening of recombinant proteins as antigens in indirect ELISA for diagnosis of bovine tuberculosis. Springer, www.springerplus.com/content 1:77.

Steele J.H., (1995). Regional and country status reports). In Theon CO and Steele J.H., (edt), Mycobacterium bovis infection in animal and Humans. Ames: Iowa state Univ press 168172.

Thoen C., Lobue P., Kantor I. (2006). The importance of Mycobacterium bovis as a zoonosis. Veterinary Microbiology, 112:339345.

Waters W. R., Buddle B. M., Vordermeier H. M., Gormley E., Palmer M. V., Thacker T. C., Bannantine J. P., Stabel J. R., Linscott R., Martel E., Milian F., Foshaug W., Weinhaupl I., Schoplf K.C., Khaschabi1 D., Kapaga A. M. and Msami H.M. (2000). Investigations on the prevalence of bovine tuberculosis and brucellosis in Dairy Cattle in Dar es Salaam Region and in Zebu Cattle in Lugoba Area, Tanzania. Tropical Animal Health and Production, 32: 147-154.
Waters W. R., Buddle B. M., Vordermeier H. M., Gormley E., Palmer M. V., Thacker T. C., Bannantine J. P., Stabel J. R., Linscott R., Martel E., Milian F., Foshaug W., and Lawrence J. C. (2011). Development and Evaluation of an Enzyme-Linked Immunosorbent Assay (ELISA) for Use in the Detection of Bovine Tuberculosis in Cattle. Clinical Vaccine and Immunology 18 (11):18821888. 